\title{
MÉTODO DE APLICAÇÃO DE ÁCIDO INDOLBUTÍRICO NO ENRAIZAMENTO DE ESTACAS HERBÁCEAS DE PESSEGUEIRO ${ }^{1}$
}

\author{
MAURO BRASIL DIAS TOFANELLI², ELIZABETH ORIKA ONO ${ }^{3}$, JOÃO DOMINGOS RODRIGUES ${ }^{4}$
}

\begin{abstract}
RESUMO - O objetivo deste trabalho foi avaliar a capacidade de enraizamento de estacas herbáceas de pessegueiro das cultivares Delicioso Precoce, Jóia 1 e Okinawa através de diferentes métodos de aplicação exógena de ácido indolbutírico (AIB). As estacas foram obtidas em setembro de 2001 e, após o preparo, foram submetidas aos tratamentos constituídos por dois métodos de aplicação de AIB: imersão rápida da base das estacas em soluções concentradas $\left(0 ; 1250 ; 2500\right.$ e $\left.3750 \mathrm{mg}^{-L^{-1}}\right)$ por 5 segundos e imersão lenta em soluções diluídas $\left(0 ; 100 ; 200\right.$ e $\left.300 \mathrm{mg} . \mathrm{L}^{-1}\right)$ por 24 horas. Observou-se que a cultivar Jóia 1 apresentou maior enraizamento (37,3\%), embora esta tenha sido estatisticamente igual à Okinawa (20,8\%), ambas tratadas com soluções concentradas de AIB. Em geral, o método de imersão rápida demonstrou melhores resultados nas variáveis avaliadas neste trabalho.
\end{abstract}

Termos para indexação: Prunus persica, propagação, estaquia, fitorregulador

\section{APPLICATION METHOD OF INDOLE-BUTYRIC ACID ON ROOTING OF PEACH HERBACEOUS CUTTINGS}

ABSTRACT - The objective of this experiment was to evaluate the effect of the application method of indole-butyric acid (IBA) on rooting of peach herbaceous cuttings. The peach cultivars used were Delicioso Precoce, Jóia 1 and Okinawa. The cuttings were taken in September, 2001 and after the preparing, they were treated with $0,1250,2500$ and $3750 \mathrm{mg} . \mathrm{L}^{-1}$ of IBA for 5 seconds (concentrated solutions) and 0, 100, 200, 300mg.L $\mathrm{L}^{-1}$ of IBA for 24 hours (diluted solutions). The best results of rooting were obtained with cultivar Jóia 1 (37,3\%), although it was statistically equal to Okinawa (20,8\%), both treated with concentrated solutions. Generally, concentrated solutions showed the best results of the evaluated parameters in this work.

Index terms: Prunus persica, propagation, cutting, plant growth regulator

O aumento na disponibilidade de mudas de qualidade e de menor custo aos fruticultores é essencial para ampliação de pomares e, consequientemente, aumento da produção de frutas no Brasil.

No caso do pessegueiro (Prunus persica (L.) Batsch), a propagação é baseada na enxertia de borbulhas de cultivares-copa sobre portaenxertos obtidos por sementes (Tofanelli et al., 2001). Para Biasi et al. (2000), este método de propagação é vantajoso para aquelas regiões próximas das indústrias de processamento, onde a obtenção dos caroços é mais prática. Mesmo assim, a propagação convencional do pessegueiro apresenta alguns inconvenientes, como risco de segregação genética dos porta-enxertos, maior tempo para produção de mudas e necessidade de mão-de-obra especializada para operação de enxertia (Tofanelli, 1999). Conforme mencionaram Chalfun \& Hoffmann (1997), a propagação do porta-enxerto através de estaca é justificada pela uniformidade da descendência e facilidade de produção da muda e da cultivar-copa, por dispensar a necessidade de enxertia, diminuindo o custo e o tempo para a produção da muda.

Vários trabalhos vêm demonstrando a necessidade de aplicação exógena de reguladores vegetais nas estacas de pessegueiro, objetivandose aumentar o percentual de enraizamento. O ácido indolbutírico (AIB) é um dos mais utilizados nesse sentido (Finardi, 1998). No entanto, o método ideal de aplicação exógena dos reguladores vegetais em estacas, para cada espécie ou cultivar, ainda não é bem definido.

Objetivou-se, neste trabalho, avaliar o efeito de métodos de aplicação do AIB no enraizamento de estacas herbáceas de cultivares de pessegueiro.

O experimento foi conduzido no Departamento de Botânica do Instituto de Biociências (IB), Universidade Estadual Paulista "Júlio de Mesquita Filho" (UNESP), Câmpus de Botucatu (SP), no período de setembro a outubro de 2001.

Em setembro de 2001, foram coletados ramos herbáceos de plantas-matrizes de pessegueiro do pomar da Coordenadoria de Assistência Técnica Integral (CATI), localizada no município de Itaberá (SP), utilizando-se das cultivares-copa Delicioso Precoce e Jóia 1 e do porta-enxerto Okinawa. Após a coleta, os ramos foram transportados imediatamente para o IB, onde, então, foram preparadas as estacas com 10 a $15 \mathrm{~cm}$ de comprimento e diâmetro de 4 a $6 \mathrm{~mm}$, mantendo-se duas folhas cortadas ao meio por estaca. As estacas foram tratadas com $0 ; 1250 ; 2500$ e 3750mg.L-1 de
AIB por cinco segundos (soluções concentradas do método de imersão rápida) ou com $0 ; 100 ; 200$ e 300mg. $\mathrm{L}^{-1}$ de AIB por vinte e quatro horas (soluções diluídas do método de imersão lenta). Após a aplicação do AIB, as estacas foram colocadas em bandejas de poliestireno expandido com 72 células, utilizando-se de vermiculita fina como substrato e colocadas em casa de nebulização por 45 dias.

O delineamento experimental adotado foi o inteiramente casualizado, com 3 repetições por parcela e 12 estacas por repetição, num esquema fatorial $3 \times 2$, constituído pelas três cultivares e pelos dois métodos de aplicação de AIB. Para a obtenção dos resultados em cada método de aplicação de AIB, considerou-se a média das quatro concentrações. As variáveis analisadas foram as porcentagens de estacas enraizadas e com calo, número de raízes primárias por estaca enraizada e comprimento médio da maior raiz por estaca enraizada.

As análises estatísticas foram realizadas comparando-se as médias pelo teste Duncan, com nível de significância de 5\%. Quando necessário, realizou-se regressão polinímia para estudo do efeito das concentrações das soluções de AIB. Efetuou-se a transformação de dados segundo a equação arco-seno $\sqrt{x / 100}$ para os dados em porcentagem e $\sqrt{x+1}$ para os valores quantitativos.

Houve influência significativa do método de aplicação e da interação deste fator com o fator cultivar no enraizamento (Tabela 1), não havendo, entretanto, efeito da cultivar. A cultivar Jóia 1 apresentou melhor enraizamento $(37,3 \%)$, embora tenha sido estatisticamente equivalente à Okinawa (20,8\%), quando ambas as cultivares foram tratadas com soluções concentradas de AIB (Tabela 1). Devido à imersão rápida ter demonstrado melhores resultados de enraizamento, foi realizada regressão polinomial para as concentrações de AIB empregadas. Através das equações demonstradas na Figura 1, obteve-se um máximo de 36,6\% de enraizamento na concentração de $1735,1 \mathrm{mg} . \mathrm{L}^{-1}$ de AIB para a cultivar Okinawa e um mínimo de $1,3 \%$ de enraizamento na concentração de 998,8mg.L L $^{-1}$ de AIB para a cultivar Delicioso Precoce, sendo que, para esta cultivar, o percentual de estacas enraizadas voltou a aumentar a partir deste ponto, obtendo-se $43,7 \%$ de enraizamento na concentração de $3750 \mathrm{mg} . \mathrm{L}^{-1}$ de AIB. A cultivar Jóia 1 não apresentou regressão significativa ao nível de $5 \%$ de probabilidade. As concentrações ideais de auxina, nas soluções utilizadas para aplicação exógena em estaca visando a aumentar o

\footnotetext{
${ }^{1}$ Trabalho (090/2002). Recebido: 07/05/2002. Aceito para publicação: 18/07/2003.

${ }^{2}$ Eng. Agrônomo, Doutorando-DPV/FCA/UNESP, Professor, FIMES, Rua 22 esq. c/ Av.21, s/n, Setor Aeroporto, Cx.P.104, 75830-000 Mineiros, GO. Email: maurobdt@bol.com.br.

${ }^{3}$ Bióloga, Professora Assistente, Doutora; ${ }^{4}$ Engenheiro Agrônomo, Professor Titular, Doutor, Departamento de Botânica, IBB/UNESP, Cx.P.510, CEP 18618-000, Botucatu, SP.
} 
enraizamento, são bastante variáveis. Um dos fatores que contribui para esta variação, é a cultivar. Isto pode ser observado na Figura 1, onde as concentrações que demonstraram maiores percentuais de estacas enraizadas, variaram de acordo com a cultivar. Tofanelli (1999) estudou o enraizamento de estacas de pessegueiros e observou que as concentrações de AIB que proporcionaram os maiores percentuais de estacas enraizadas, também não foram as mesmas entre as cultivares utilizadas no trabalho, tendo verificado que as cultivares Ouromel, Pérola de Mairinque e Tropical apresentaram máximos de enraizamento com 3000mg.. - $^{-1}$ de AIB (35,33\%, 69,0\% e $56,67 \%$, respectivamente) e a cultivar Biuti com 2026,53mg.L $\mathrm{L}^{-1}$ de AIB $(36,78 \%)$.

A formação de calo foi influenciada pela cultivar, pelo método de aplicação e pela interação destes fatores (Tabela 1). Com o desdobramento da interação, pôde-se observar que as cultivares Jóia $1(15,1 \%)$ e Delicioso Precoce $(9,8 \%)$ apresentaram as maiores porcentagens de estacas com calos quando foram tratadas com as soluções concentradas de AIB. A porcentagem de formação de calo foi crescente no sentido: cultivar Okinawa, Delicioso Precoce e Jóia 1. A cultivar Jóia 1 apresentou a maior porcentagem de estacas enraizadas e, também, a maior porcentagem de estacas com calos. Antunes et al. (2000) observaram o mesmo comportamento em estacas de amora-preta quando obtiveram padrão similar entre enraizamento e formação de calos, e mencionaram que estes dois processos se completam. Já Ono et al. (1992) afirmaram que a calogênese não é interessante, demonstrando que os calos formados em estacas de cafeeiro (Coffea arabica) não se diferenciaram em raízes.

A cultivar Jóia 1 foi a que apresentou o maior número de raízes (11,3 raízes) e o maior comprimento de raiz $(7,0 \mathrm{~cm})$, quando as estacas foram tratadas com soluções concentradas de AIB, embora tenha sido estatisticamente equivalente à cultivar Okinawa $(5,0 \mathrm{~cm})$ (Tabela 1$)$. Isto sugere que um maior número de raízes pode resultar em um maior comprimento de raiz nas estacas e que cada cultivar apresenta comportamento diferente quanto à formação de raízes. Sharma \& Aier (1989) demonstraram que, entre as ameixeiras (Prunus spp) "Santa Rosa", "Eauty", "Greengage" e "Early Transparent Gage", a primeira apresentou o maior enraizamento, número e comprimento de raiz.

TABELA 1 - Porcentagens de estacas enraizadas e com calo, número de raízes e comprimento de raiz em estacas de pessegueiro tratadas com diferentes métodos de aplicação de AIB. Médias em função da interação cultivar $\times$ método de aplicação. Botucatu, FCA/UNESP, 2003.

\begin{tabular}{llcc}
\hline Variável & Cultivar & \multicolumn{2}{c}{ Método de aplicação do AIB } \\
\cline { 3 - 4 } & & Imersão lenta & Imersão rápida \\
\hline \multirow{2}{*}{ Enraizamento (\%) } & Delicioso Precoce & $2,1 \mathrm{aB}$ & $15,7 \mathrm{bA}$ \\
& Okia 1 & $1,8 \mathrm{aB}$ & $37,3 \mathrm{aA}$ \\
& Delicioso Precoce & $0,2 \mathrm{bB}$ & $9,8 \mathrm{aA}$ \\
\multirow{2}{*}{ Formação de } & Jóia 1 & $3,4 \mathrm{aB}$ & $15,1 \mathrm{aA}$ \\
calo (\%) & Okinawa & $5,1 \mathrm{aA}$ & $2,1 \mathrm{bA}$ \\
\hline \multirow{2}{*}{ Número de raízes } & Delicioso Precoce & $0,4 \mathrm{aB}$ & $5,0 \mathrm{cA}$ \\
& Jóia 1 & $0,3 \mathrm{aB}$ & $11,3 \mathrm{aA}$ \\
& Okinawa & $0,5 \mathrm{aB}$ & $8,0 \mathrm{bA}$ \\
\hline \multirow{2}{*}{ Comprimento de } & Delicioso Precoce & $1,2 \mathrm{aA}$ & $2,5 \mathrm{bA}$ \\
\multicolumn{1}{c}{ raiz (cm) } & Jóia 1 & $0,4 \mathrm{aB}$ & $7,0 \mathrm{aA}$ \\
& Okinawa & $1,6 \mathrm{aB}$ & $5,0 \mathrm{abA}$ \\
\hline
\end{tabular}

Médias seguidas por letras minúsculas na coluna e maiúsculas na linha diferem entre si, pelo teste Duncan $(\mathrm{P}<0,05)$.

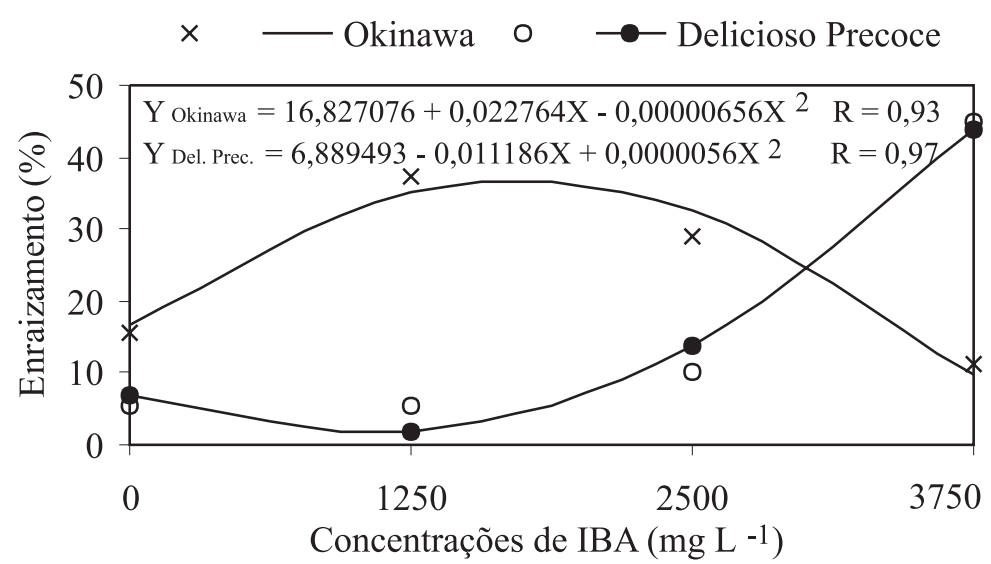

FIGURA 1 - Efeito do AIB no enraizamento de estacas de pessegueiro das cultivares Okinawa e Delicioso Precoce. Botucatu, FCA/ UNESP, 2003

\section{AGRADECIMENTOS}

Os autores agradecem ao Engenheiro Agrônomo Emmanuel Afonso Souza Moraes, Diretor do Departamento de Sementes, Mudas e Matrizes da CATI, Itaberá (SP), pelo fornecimento do material de pesquisa, e aos funcionários, pelos serviços prestados durante a estada nesta repartição. À coordenadoria de Aperfeiçoamento de Pessoal de Nível Superior (CAPES), pelo apoio financeiro.

\section{REFERÊNCIAS}

ANTUNES, L.E.C., CHALFUN, N.N.J., REGINA, M. de A. Propagação de cultivares de amoreira-preta (Rubus spp) através de estacas lenhosas. Revista Brasileira de Fruticultura, Jaboticabal, v. 22, n. 2, p.195-199, ago. 2000.

BIASI, L.A., STOLTE, R.E., SILVA, M. da S. Estaquia de ramos semilenhosos de pessegueiro e nectarina. Revista Brasileira de Fruticultura, Jaboticabal, v.22, n.3, p.421-425, dez 2000.

CHALFUN, N.N.J.; HOFFMANN, A. Propagação do pessegueiro e da ameixeira. Informe Agropecuário, Belo Horizonte, v.18, n.189, p.23-29, 1997.

FINARDI, N.L. Método de propagação e descrição de porta-enxertos, In: MEDEIROS, C.A.B., RASEIRA, M. do C.B. (Ed.) A cultura do pessegueiro, Pelotas: EMBRAPA/CNPAT, 1998. cap. 1, p.100-128.

ONO, E.O., RODRIGUES, J.D., PINHO, S.Z. do. Interações entre auxinas e ácido bórico, no enraizamento de estacas caulinares de Coffea arábica L. cv. Mundo Novo. Scientia Agricola, Piracicaba, v. 49, n. 1, p. $23-$ 27, 1992

SHARMA, S.D., AIER, N.B. Seasonal rooting behaviour of cuttings of plum cultivars as influenced by AIB treatments. Scientia Horticulturae, Amsterdam, v.40, n.4, p.297-303, nov 1989.

TOFANELLI, M. B. D. Enraizamento de estacas lenhosas e semilenhosas de cultivares de pessegueiro em diferentes concentrações de ácido indolbutírico. 1999. 87f. Dissertação (Mestrado em Agronomia). Universidade Federal de Lavras, Lavras - MG. 1999.

TOFANELLI, M.B.D., CHALFUN, N.N.J., HOFFMANN, A., CHALFUN JÚNIOR, A. Uso do ácido indolbutírico na propagação de cultivarescopa de ameixeira através de estacas lenhosas. Científica Rural, Bagé, v.6, n.1,p.115-121, 2001 